\title{
Age-related macular degeneration: current treatments
}

\author{
Jean Pierre Hubschman \\ Shantan Reddy \\ Steven D Schwartz \\ Jules Stein Eye Institute, \\ Department of Ophthalmology, \\ University of California, David Geffen \\ School of Medicine, Los Angeles, \\ California, USA
}

\begin{abstract}
Purpose: Although important progress has been made in understanding age-related macular degeneration (AMD), management of the disease continues to be a challenge. AMD research has led to a widening of available treatment options and improved prognostic perspectives. This essay reviews these treatment options.

Design: Interpretative essay.

Methods: Literature review and interpretation.

Results: Current treatments to preserve vision in patients with non-exudative AMD include antioxidant vitamins and mineral supplementations. Exudative AMD is currently most often treated monthly with anti-VEGF intra-vitreal injections. However, investigators are beginning to experiment with combination therapy and surgical approaches in an attempt to limit the number of treatment and reduce the financial burden on the health care system.

Conclusion: By better understanding the basis and pathogenesis of AMD, newer therapies will continue to be developed that target specific pathways in patients with AMD, with the hoped for outcome of better management of the disease and improved visual acuity.
\end{abstract}

Keywords: age-related macular degeneration, VEGF, photodynamic therapy, laser, surgery

\section{Introduction}

In industrialized nations, age-related macular degeneration (AMD) is the leading cause of vision loss and blindness in people over age $65 .{ }^{1-4}$ As the disease affects the central regions of the retina and choroid, central visual loss can ensue. Approximately $30 \%$ of adults aged 75 or older have some signs of maculopathy, and $6 \%$ to $8 \%$ of these individuals are afflicted with the advanced stages of AMD. Due to increased life expectancy and current demographics, the prevalence of AMD is expected to double by the year $2020 .^{5-7}$

There are two major clinical presentations of AMD: non-exudative or atrophic AMD, which is characterized by the degeneration of choriocapillaries, retinal pigment epithelium (RPE) and neurosensory retina; and neovascular or exudative AMD, which is characterized by the development of serous RPE (retinal pigment epithelium) detachments and/or new choroidal vessels that can lead to bleeding, exudation, and eventual scar formation. Although the exudative form of AMD only accounts for $10 \%$ to $20 \%$ of the overall incidence of AMD, it is responsible for over $90 \%$ of cases with severe visual loss. ${ }^{8,9}$

The management of either type of AMD continues to be a challenge for patients, ophthalmologists, and the healthcare system. The primary purpose of AMD disease management is to minimize visual loss and the related physical and emotional impairment, and to optimize vision-related quality of life. Recently, the important progress made in the comprehension and knowledge about basic pathologic mechanisms in both types of AMD has led to novel developments in therapeutic strategies resulting in a widening of available treatment options and improved prognostic perspectives. ${ }^{10}$ 
Treatment options span a broad range of therapeutic approaches, including thermal laser photocoagulation, surgical approaches (excision, displacement, or transplantation), and new treatments targeting the CNV component and its pathogenic cascade, such as verteporfin with photodynamic therapy (vPDT) and more recently anti-vascular endothelial growth factor (VEGF) therapies. Because of relatively revolutionary efficacy results using anti-VEGF therapy, we can now, for the first time, anticipate that over a quarter of our patients with exudative AMD will show visual improvement. Emerging strategies such as RNA interference, gene therapy, and new treatment targets such as integrin inhibitors and complement modifying agents great promise and are under study. This review will focus on summarizing the actual therapeutic options in the clinical management of the different forms of AMD and provide an overview about therapeutic perspectives.

\section{Current treatment in clinical use Prevention in intermediate and advanced AMD}

It is well recognized that oxidative stress likely contributes to the pathogenesis of AMD. The retina's defenses to such processes include glutathione (GSH) peroxides, catalases, and antioxidant nutrients such as vitamins $\mathrm{E}$ and $\mathrm{C}$ and carotenoids. With this understanding, it has been hypothesized that people with low levels of these antioxidants may be more prone to oxidative damage in the retina, which may ultimately lead to AMD. It is reasonable to speculate that consuming higher levels of these antioxidants may protect an individual from developing AMD. This was hypothesized and proven by the Age-Related Eye Disease Study Group who showed that antioxidants and zinc supplements could reduce the risk of progression in some forms of AMD. More specifically, early AMD (AREDS category 2 ), characterized by small and intermediate drusen with no or minimal pigment epithelial abnormalities in the macula, progressed to advanced AMD in only $1.3 \%$ of cases at 5 years. ${ }^{11}$ Alternatively, intermediate AMD (AREDS category 3), charaterized by extensive medium-sized drusen ( $\geq 125 \mu \mathrm{m}$ in diameter) in one or both eyes, progressed to advanced AMD in 18\% of cases. No evidence was found to support the use of antioxidant vitamins and mineral supplementation in early AMD. Conversely, patients with either intermediate or advanced AMD (in one eye) benefited from a combination of antioxidant vitamin and mineral supplementation (AREDS formulation: vitamin C $500 \mathrm{mg}$, vitamin E $400 \mathrm{IU}$, beta-carotene $15 \mathrm{mg}$, zinc oxide $80 \mathrm{mg}$, and cupric oxide $2 \mathrm{mg}$ ). The relative risk of developing advanced AMD (in the other eye in the advanced AMD group) was reduced by $25 \%$, and the relative risk of vision loss of 3 or more lines was reduced by $19 \% .{ }^{11}$ Since studies also found that beta-carotene increased the risk of lung cancer in smokers, it was recommended that smokers consider omitting beta-carotene from the formulation. ${ }^{12,13}$ Lutein and zeaxanthin, major components in macular pigment, may reduce the likelihood of having advanced AMD. ${ }^{14}$ Direct evidence of neuro-protection is still lacking but it is hypothesized that macular xanthophylls play a role as: an important structural molecule within cell membrane, a modulator of intra- and extra-cellular reduction-oxidation balance; and a short-wavelength light (which is damaging to retinal tissues) filter. ${ }^{15}$ In the same way, omega-3 LCPUAs present some structural and functional properties which indicate a probable role in visual-sensory process and as a protective factor against retinal diseases. ${ }^{16}$ Indeed, inverse relationship of dietary omega-3 LCPUFA intake with advanced AMD has been reported in different studies. ${ }^{17,18}$ Studies investigating the impact of lutein and omega-3 fatty acids on the incidence and progression of AMD provided conflicted results, though they have been shown to be non-toxic to the retina. In response, AREDS 2, which started in late 2006, is a multi-center randomized phase III study designed to assess the effects of oral supplementation of high doses of macular xanthophylls (lutein and zeaxanthin) and omega-3 LCPUFAs [docosahexaenoic acid (DHA) and eicosapentaenoic acid (EPA)] for the treatment of AMD and cataract. This study will enroll 4000 subjects for a 6-year period.

In addition to the intake of vitamin and minerals supplements described by the AREDS study, stopping smoking and a healthy diet are strongly recommended.

\section{Treatment of advanced AMD}

\section{Exudative AMD}

\section{Laser photocoagulation}

Thermal laser photocoagulation was first introduced in an attempt to halt the progression of neovascular AMD. The Macular Photocoagulation Study (MPS) Group trials assessed laser treatment for CNV in three locations: extra-foveal $(\geq 200 \mu \mathrm{m}$ from the geographic center of the foveal avascular zone), juxta-foveal (1-199 $\mu \mathrm{m}$ ), and sub-foveal (extending directly beneath the geographic center of the foveal avascular zone). ${ }^{19-23}$ In each trial, the control group of untreated eyes provided natural history data. Photocoagulation of well-demarcated extra-foveal CNV resulted in a significant 
reduction in the risk of severe vision loss over the first 2 years. A recurrence rate of 54\% reduced this benefit over the subsequent 3 years of follow-up. Laser photocoagulation, however, did not result in better vision over a longer period of time. The relative risk of severe visual loss of 6 or more lines among untreated eyes compared to treated eyes was 1.5 from 6 months through 5 years. ${ }^{19}$ Photocoagulation of well-demarcated juxta-foveal CNV membranes resulted in a small overall treatment benefit. ${ }^{20-23}$ The benefit was limited because of the high rate of persistence and recurrence (80\%) over a 5-year observation period. ${ }^{24-26}$ Laser photocoagulation of sub-foveal CNV was primarily recommended for lesions smaller than two optic discs and with visual acuity below $20 / 200$. Unfortunately, $82 \%$ of treated subjects developed visual loss below 20/200 and the laser photocoagulation of sub-foveal $\mathrm{CNV}$ is no longer recommended as a primary treatment option for such lesions.

In summary, while the MPS group trials demonstrated an effective therapy for extra-foveal $\mathrm{CNV}$, visual results for sub-foveal disease and the high rate of foveal recurrence within the first year were disappointing to patients and to their physicians.

\section{Photodynamic therapy using verteporfin (Visudyne ${ }^{\circledR}$ )}

Photodynamic therapy (PDT) with verteporfin (Visudyne ${ }^{\circledR}$ ) (vPDT) emerged as a welcome alternative to thermal laser for the treatment of CNV. This technique employs intravenous administration of a pharmacological photo-sensitizer (eg, verteporfin) followed by physical activation of the substance using a $689 \mathrm{~nm}$ laser light. Excitation of the photo-sensitizer initiates a photochemical reaction involving singlet oxygen and reactive oxygen intermediates, which damage endothelial cells lining the CNV and can lead to selective occlusion of the CNV with less severe effects on the retina and underlying choroid. Because a non-thermal light intensity is used to induce the photochemical oxidation within the vascular endothelium, thermal tissue damage does not theoretically occur but vaso-occlusion with concomitant thrombosis of the normal choriocapillaris has been documented. ${ }^{27}$ Moreover, the thrombotic effect induce an hypoxia which locally increase the expression of VEGF. ${ }^{28}$ The Treatment of Age Related Macular Degeneration with Photodynamic Therapy (TAP) study found a benefit to treatment after 1 and 2 years. ${ }^{29-31}$ Subjects with sub-foveal lesions (containing any proportion of a classic component) of up to $5400 \mu \mathrm{m}$ in the greatest linear diameter were enrolled in these trials, and pre-randomization visual acuity ranged from an approximate Snellen equivalent of $20 / 40$ to $20 / 200$. A benefit was found for the entire population, with 53\% of the vPDT-treated subjects and $38 \%$ of the sham-treated subjects losing fewer than 15 letters in visual acuity at 2 years $(\mathrm{p}<0.001)$. Sub-group analysis by angiographic classification revealed that the benefit was largest in predominantly classic lesions (in which the area of classic CNV is greater than $50 \%$ of the entire lesion). In this type of lesion, 59\% of vPDT-treated eyes compared with $31 \%$ of sham-treated eyes lost fewer than 15 letters. An improvement in vision by 15 letters or more was seen in only $9 \%$ of treated subjects (including predominantly and minimally classic lesions) at the 24 month visit.

The Verteporfin in Photodynamic therapy (VIP) trial enrolled subjects with sub-foveal CNV lesions composed of angiographically occult lesion sub-type only, and with a presumed recent disease progression (vision loss by at least one line, new hemorrhage, or an enlargement of the CNV by at least $10 \%$ seen by angiography). At 2 years, $45 \%$ of vPDT-treated eyes compared to $32 \%$ of sham-treated eyes lost fewer than 15 letters and an improvement in vision by at least 15 letters was seen in 5\% of treated subjects. Loss of 30 letters or more was observed in $29 \%$ of eyes in the vPDT group versus $47 \%$ of eyes in the placebo group. Sub-group analysis revealed that $\mathrm{CNV}$ with relatively small size (less than 4 MPS disc areas) or relatively low visual acuity ( $<65$ letters) had better outcomes. ${ }^{32}$ In this sub-group, $51 \%$ of the vPDT-treated eyes lost less than 15 letters versus $25 \%$ of placebo-treated eyes. The benefit or stabilization achieved during the first 2 years was often maintained for at least the following 3 years.

The ocular and systemic safety of verteporfin therapy was confirmed in the TAP and VIP trials. ${ }^{33}$ Acute severe visual loss (loss of more than 20 letters or 4 lines of vision within 7 days of verteporfin therapy) was noted however $(0.7 \%$ in the TAP investigation and $4.9 \%$ in the VIP trial) and was more often seen in the treatment of large occult lesions with better initial visual acuity. ${ }^{34}$

Participants in the TAP study received on average 5 treatments over the 2 years and the risk ratio of losing 3 or more lines and 6 or more lines of visual acuity was 0.77 (95\% confidence interval 0.69-0.87) and $0.62(95 \%$ confidence interval $0.50-0.76)$, respectively. ${ }^{33}$ The frequency of re-treatments decreased from an average of 3.4 in the first year, to 2.2 in the second year, to 0.4 by the fourth year (TAP Study Group 2005). An analysis of treatment outcomes by lesion size following vPDT from the TAP and VIP studies suggested that therapy might reduce the risk of visual loss in small, minimally classic lesions. ${ }^{35}$

In summary, the TAP and VIP studies provided evidence of the efficacy and safety of the verteporfin therapy. 
This therapy reduces the risk of further loss in vision by $50 \%$; however, an improvement in vision was still a rare event. Predominantly classic or purely occult lesions smaller than four disc diameters that showed recent progression were shown to have better outcomes. Considering the durability and need for fewer repeated treatments, in the pre- anti-VEGF era, vPDT was an appropriate therapy for sub-foveal CNV, new or recurrent, where the classic component is greater than $50 \%$ of the entire lesion $(\leq 5400 \mu \mathrm{m}$; or in an occult CNV when the visual acuity is worse than $20 / 50$ or greater than 20/50 with a lesion size less than a disc diameter).

\section{Anti-VEGF therapies}

The VEGF family consists of 6 growth factors (VEGF-A, $-\mathrm{B},-\mathrm{C},-\mathrm{D},-\mathrm{E}$, and placental growth factor or PIGF) that bind three distinct tyrosine kinase receptors (VEGF-R1, VEGF-R2, and VEGF-R3). VEGF-R2 seems to be the functional receptor that mediates endothelial cell migration. ${ }^{36}$ Different factors appeared to be regulators for VEGF-induced angiogenesis, but hypoxia seems to be the most important one. ${ }^{37}$ When activated angiogenesis and vascular permeability induced by VEGF are mediated by different pathways. ${ }^{38,39}$

Multiple studies have suggested that vascular endothelial growth factor (VEGF) increases vascular permeability and is involved in the pathogenesis of neovascularization in human eye disease. ${ }^{40}$ Current approaches to inhibit VEGF involve binding it to a molecule that prevents receptor 0 -ligand interaction, thus incapacitating the effect of VEGF on the local environment. Options currently include either a full-length recombinant monoclonal antibody (bevacizumab) or a highly affinitized fragment of the antibody (ranibizumab), or a pegylated aptamer (pegabtanib sodium).

Intravitreal injection of pegaptanib $\left(\right.$ Macugen $\left.^{\circledR}\right)$ : Vascular endothelial growth factor 165 has been found to play a major role in blood-retinal barrier breakdown and pathological intraocular neovascularization. ${ }^{41}$ Pegaptanib sodium is an aptamer composed of ribonucleic acids, which competitively blocks VEGF 165 and selectively inhibits angiogenesis and leakage. ${ }^{42}$ Pegaptanib has to be injected into the vitreous cavity and re-injections have to be performed every 6 weeks as the molecule is rapidly degraded enzymatically by intraocular nucleases. Pegaptanib was the first biological molecule to selectively counteract one of the main pathogenic stimuli of CNV, while preserving all the physiologic structures of the macula.

The efficacy of pegaptanib has been evaluated in a randomized, double-masked, multicenter, dose ranging, controlled clinical trial (VEGF Inhibition Study in Ocular
Neovascularization (VISION)). ${ }^{43}$ A total of 1,186 subjects with either classic, minimally classic, or occult membranes were included. An intravitreous injection of pegaptanib at a dose of $0.3 \mathrm{mg}, 1 \mathrm{mg}$, or $3 \mathrm{mg}$ or a sham injection was administered every 6 weeks over a period of 48 weeks. Subjects enrolled in the trial were allowed one vPDT before the start of the study and any number of vPDT treatments throughout the study period at the discretion of the investigator. The efficacy was demonstrated, for all three doses of pegaptanib. In the group given pegaptanib at $0.3 \mathrm{mg}$ (which was identified as the lowest safe and effective dosage), $70 \%$ of subjects lost fewer than 15 letters of visual acuity, as compared with $55 \%$ of subjects in the control group $(\mathrm{p}<0.001)$. The risk of severe visual loss (loss of 30 letters or more) was reduced from $22 \%$ in the sham-injection group to $10 \%$ in the group receiving $0.3 \mathrm{mg}$ of pegaptanib $(\mathrm{p}<0.001)$. More subjects receiving pegaptanib $(0.3 \mathrm{mg})$, as compared to the sham injection, maintained or gained visual acuity ( $33 \%$ vs $23 \%$; $=0.003)$. The beneficial effect was seen for all types of neovascularization. Subgroup analysis did, however, reveal a slightly larger benefit in minimally classic lesions, with stabilization in $76 \%$ of eyes as compared to $54 \%$ in the sham group. A 2-year evaluation showed that mean visual acuity was maintained in subjects continuing with $0.3 \mathrm{mg}$ pegaptanib. ${ }^{44}$ In order to maintain the initial stabilization rates, the injections of pegaptanib had to be given throughout the entire 2 years. Twenty-six percent of subjects discontinuing treatment after the first year experienced an additional loss of $\geq 15$ letters versus $16 \%$ in the continued group. Despite treatment, the total size of the lesion increased from 3.7 disk diameters at baseline to 5.5 at the 2-year follow-up. Six percent of treated eyes improved by 3 lines compared to $2 \%$ in the sham group. No statistical difference was found between the various $\mathrm{CNV}$ subgroups, however predominantly classic lesions tended to do better. Early detection may result in superior visual outcomes (improvement or stabilization in 76\% versus $50 \%$ in the usual care group). ${ }^{45}$

The safety profile of pegaptanib is favorable at 2 years. The most common ocular adverse events were transient, mild to moderate in intensity, and related to injection preparation and procedure. The injection procedure itself can lead to serious ocular adverse events at a rate of 2.1 to $2.3 \%$ /year (endophthalmitis $1.3 \%$ /patient, retinal detachment $0.6 \%$ /patient, traumatic cataract $0.6 \%$ /patient). In events associated with systemic VEGF inhibition, or in severe ocular complications when compared to sham treated subjects, there was no evidence of an increase in deaths. 
Pegaptanib was approved as the first anti-VEGF agent by the FDA in December 2004 and by the European Medicines Agency in January 2006 for all lesion types in neovascular AMD. Similar to vPDT monotherapy, the benefit of a pegaptanib is limited to visual stabilization with an overall inability to improve vision. This warrants clinicians to examine the risks of intravitreal injections versus vPDt.

It is accepted now that intravitreal injections are well tolerated and safe when performed according to protocol. Though there is an increase in risk of endophthalmitis or retinal detachment with intravitreal injections, RPE atrophy and photoreceptor loss than can ensue after vPDt is far less common with anti-VEGF therapy. In our opinion, the benefits of pegaptanib therapy for AMD outweigh the risks even though pegaptanib treatment entails intravitreal injections every 6 weeks instead of PDT every 12 weeks. vPDT is not equally efficacious across the lesion subtypes and sizes, whereas pegaptanib has effect with all lesion subtypes and pharmacotherapy opens up the possibility of combination therapy in attacking neovascularization through multiple ways.

Intra-vitreal injection of ranibizumab (Lucentis ${ }^{\circledR}$ ): Ranibizumab is a humanized IgG1 kappa recombinant monoclonal antibody fragment that recognizes and binds extra-cellular VEGF with high affinity. Ranibizumab has the ability to bind and inactivate all isoforms of VEGF-A including the soluble VEGF fragments $(110,121$, and 165) and the tissue-bound isoforms 189 and $206 .{ }^{46}$ Theoretically, ranibizumab, due to its small molecular size, is able to penetrate the retina and reach the sub-retinal space and inhibit VEGF. Its half life is 2 to 4 days which results in a rapid systemic clearance and improved safety. ${ }^{41}$

A large randomized, multicenter, sham controlled phase III study (MARINA study) enrolled 716 subjects with minimally classic and occult lesions with evidence of recent disease progression. Subjects were randomized to 2 treatment groups and 1 sham group. The treatment groups received a mean of 22 injections (monthly interval) of ranibizumab ( 0.3 or $0.5 \mathrm{mg}$ ) through 24 months. Another prospective randomized phase III trial, (ANCHOR), enrolled 423 subjects with predominantly classic sub-foveal lesions. This study included a monthly injection of either 0.3 or $0.5 \mathrm{mg}$ of ranibizumab versus the vPDT treated group. The PIER study included 184 subjects with all types of macular exudative lesions and evaluated the efficacy and safety of ranibizumab, which was administered monthly for 3 doses, followed by a fixed regimen of re-treatments in 3-month intervals. ${ }^{47}$
The results of the MARINA and ANCHOR studies showed that $95 \%$ to $96 \%$ of the subjects treated with ranibizumab $(0.5 \mathrm{mg})$ maintained stable vision within 3 lines (compared to $62 \%-64 \%$ of sham or PDT group treated eyes) at 1 year. ${ }^{48-50}$ Thirty-four percent to $40 \%$ of the treated eyes improved by $\geq 3$ lines of vision (compared to $6 \%$ in the vPDT group and $4 \%$ in the sham group). In the PIER study, only $13 \%$ of the treated subjects experienced an improvement in vision, which highlights the importance of an individualized re-treatment regimen on a monthly basis. On average, subjects treated with Lucentis in the MARINA study experienced an improvement from baseline of 6.6 letters at 2 years compared to a loss of 14.9 letters in the sham group. In the ANCHOR study, subjects treated with ranibizumab, on average, experienced a 11.3 letter gain from baseline at one year compared to a loss of 9.5 letters in the vPDT group. Up to $40 \%$ of subjects treated with ranibizumab achieved vision of 20/40 or better. Patient age, initial visual acuity, lesion composition or size did correlate with the functional results (visual acuity stabilization or improvement).

The Optical Coherence Tomography Imaging Patients with Neovacular AMD Treated with Intra-Ocular Lucentis (PrONTO) study evaluated an OCT-guided, variable-dosing regimen with intra-vitreal ranibizumab for the treatment of subjects with neovascular age-related macular degeneration. ${ }^{51}$ This was a prospective open-label study which evaluated whether OCT criteria at monthly intervals could be used to guide re-treatment with ranibizumab. Patients were enrolled within the study regardless of lesion type or previous treatment. Patients received intravitreal $0.5-\mathrm{mg}$ ranibizumab injections at 0,1 , and 2 months. For the remainder of the study, strict criteria were established to determine whether the patient received additional intra-vitreal ranibizumab. The criteria used were: 1) decrease in acuity of 5 letters and any fluid by OCT, 2) increase in central macular thickness of $100 \mu \mathrm{m}$ even if visual acuity did not, 3) new hemorrhage, 4) new classic CNV by fluorescein angiography, and 5) persistent fluid from $\mathrm{CNV}$ after last treatment. Forty patients were enrolled in the study and received a total of 222 injections over the 12 months of follow-up. On average, patients gained 9.3 letters at 12 months with $95 \%$ of patients stable or improved. Only $37.5 \%$ of patients needed 3 or $3+1$ dose of intra-vitreal ranibizumab to quiesce the choroidal neovascular membrane. The mean time to first retreatment was 4.3 months.

Preliminary results from the PrONTO study suggest that fewer injections will most likely result in visual acuity improvements similar to the results from the phase III trials 
and suggest that less frequent treatment with ranibizumab is possible by using a variable dosing regimen with OCT. However, the Pronto study does not bring the same level evidence that MARINA or ANCHOR brought due to its small sample size (40 patients) and limited follow-up and treatment recommendations warrant further investigations and should be practiced with caution.

Systemic safety was excellent and the death rate did not differ between the groups. The frequency of systemic thrombo-embolic events (myocardial infarcts), however, was slightly higher (not statistically significant) in subjects treated with $0.5 \mathrm{mg}$ of ranibizumab as compared to the other treatment groups. ${ }^{52}$ A phase IIIb SAILOR (Safety Assessment of Intra-vitreal Lucentis for Age-Related Macular Degeneration) study and the HORIZON trial which is a long-term extension study that follow-up subjects who participated in the MARINA and ANCHOR trial for 5 years are underway to evaluate the safety of ranibizumab. The ranibizumab at a dose of $0.5 \mathrm{mg}$ was approved by the FDA in June 2006 and by the EMEA in January 2007 for the treatment of all lesion types in exudative AMD. An individual monthly evaluation allowing treatment on demand when leakage or activity of the neovascular lesion is detected is recommended.

Intra-vitreal injection of bevacizumab (Avastin ${ }^{\circledR}$ ) - off-label therapy: Bevacizumab is a full-length monoclonal antibody that binds all iso-forms of VEGF-A. This drug reduces angiogenesis and vascular permeability after an intra-vitreal injection. Bevacizumab has been FDA approved in the treatment of metastatic colorectal carcinoma. Preliminary reports have showed promising results regarding the use of intra-vitreal injections of bevacizumab in the treatment of neovascular AMD. A phase I study (SANA, Systemic Avastin for neovascular AMD) in 15 subjects evaluated the infusion of $5 \mathrm{mg} / \mathrm{kg}$ of bevacizumab in 2-week intervals. ${ }^{53}$ A significant functional and anatomical improvement was described at a short-term follow-up (12 weeks). The only adverse event identified was a mild elevation of the systolic blood pressure. Short-term uncontrolled retrospective case series showed no apparent short-term safety concerns for intravitreal bevacizumab injections for $\mathrm{CNV}$, and treated eyes had a significant decrease in macular thickness and improvement in visual acuity. ${ }^{54-57}$ Monthly bevacizumab intra-vitreal injections have also been tested for CNV which did not respond to other treatments (vPDT and/or pegaptanib). ${ }^{58}$ Seventy-eight percent of eyes experienced an anatomical and functional benefit after treatment. Ten rabbit eyes were injected to evaluate retinal penetration and toxicity of bevacizumab, and ERG and PEV responses were similar in injected and controlled eyes showing that bevacizumab was non-toxic to the retina of rabbits. ${ }^{59}$

Finally, a randomized, multicenter, clinical trial called CATT (Comparison of ARMD Treatments Trials) will include 1200 subjects and compare the efficacy and safety of bevacizumab and ranibizumab. The level of efficacy, safety, dosage, and re-treatment schedule are unknown until the results of the study are revealed. Currently, we may want to consider an off-label use of bevacizumab only because its cost is less as compared to other available anti-VEGF drugs. In summary, this off-label approach appears to have a beneficial effect in the short-term treatment of all subtypes of CNV in AMD, but questions about its safety and long-term efficacy are still unanswered.

Anti-VEGF therapies are an important breakthrough in exudative AMD, but they present issues that need to be explained. First, resistance to anti-angiogenic therapy cannot be dismissed. . $^{40,50,60}$

Small case series suggest an increased rate of RPE tears after an injection though there is no study suggesting that this is higher than the rate in untreated patients after one year of evolution. ${ }^{61-64}$ Finally, the long-term systemic safety above 2 years has not yet been addressed. ${ }^{65,66}$ It is unlikely, however, that we will have better results in terms of safety concerns given the reduced life expectancy of patients with AMD and concomitant systemic disease (mean 7 years). Most patients are likely to die 5 to 10 years after beginning therapy.

Vascular-endothelial growth factor has many essential functions, including the formation of collateral vessels after ischemia as well as neurotrophic properties. Despite intra-vitreous injection, systemic absorption occurs and long-term treatment with repeat injections may cause chronic inhibition of the VEGF and its associated adverse effects. Ongoing safety analysis is being performed in the SAILOR trial, the HORIZON trial (extension study of MARINA and ANCHOR), as well as the CATT trial. The anti-VEGF re-treatment strategy is another question still unanswered. A combination of a clinical examination and a qualitative OCT to guide anti-VEGF re-treatment, as suggested in the PrONTO study, seems to achieve equivalent results when compared to giving monthly injections. ${ }^{52}$

\section{Combined therapies}

The pathophysiology of CNV is complex and a combination of various therapies that have synergistic modes of action may be able to target the multiple components of CNV. Theoretically, this can reduce the frequency of re-treatments 
and allow stabilization of the visual improvement above that offered by monotherapy alone.

Combination of verteporfin-PDT and steroids: PDT with verteporfin produces reactive oxygen species that induce closure of the CNV. Unfortunately, there is also a release of several potent mediators of the immune system (complements, clotting cascades, proteinases, cytokines, and growth factors), which can contribute to the re-growth of the CNV. ${ }^{67}$ Corticosteroids are known to exert an inhibitory effect on VEGF expression, vascular permeability, and inflammatory pathway. The complementary action of the anti-inflammatory and/or anti-angiogenic drugs given in combination with vPDT may improve its efficacy. Intra-vitreal triamcinolone is the drug most tested. ${ }^{68-70}$ This combination (triamcinolone with vPDT) showed an improvement in vision in most subjects that was maintained during 2 years of follow-up, and re-treatment numbers were lower than that expected from monotherapy. ${ }^{71}$ Furthermore, despite the well known side effects of intra-vitreal corticosteroids (cataract, elevations in intraocular pressure, and endophthalmitis) the preliminary findings suggest that the combination is safe and may be considered as a useful alternative, particularly in pseudo-phakic patients.

A new type of steroid, anecortave acetate, which is an angiostatic steroid that minimizes the glucocorticoid activity (no cataract or elevations in intraocular pressure), is under evaluation in combination with vPDT. Preliminary data reveal a trend towards more beneficial outcomes than with single treatment alone..$^{72,73}$

Verteporfin PDT with anti-angiogenic therapies: Treatments for CNV can be directed at either the vascular component of the CNV (the new vessels that proliferate and leak blood and fluid) or the angiogenic components that lead to the development of the condition. The combination of VPDT which targets the vascular components and the anti-VEGF therapy which targets key mediators of the angiogenic cascade, may have an additive and synergistic effect to reduce the frequency of treatment. ${ }^{74}$ Moreover, the expression of VEGF is increased after vPDT therapy and contributes to the re-growth of the CNV. ${ }^{67-75}$ Different studies have evaluated this combination. ${ }^{76}$

The FOCUS study as well as the PROTECT trial evaluated the safety and efficacy of ranibizumab in combination with vPDT versus vPDT alone. At 1 year, $91 \%$ of treated subjects had stable vision compared with $68 \%$ under vPDT alone. The number of vPDT sessions was 2.3 in the combinationtreated subjects versus 3.4 in monotherapy. In the same way, $31 \%$ of the combination-treated eyes gained at least
3 lines versus 15\% in the vPDT monotherapy group. Although ranibizumab treatment increased the risk of serious intraocular inflammation, affected subjects, on average, still experienced visual acuity benefit. ${ }^{77,78}$ Two non-randomized case series evaluated the combination of bevacizumab with vPDT. The results suggested that this combination may be useful by reducing re-treatment rate and improving visual acuity. ${ }^{79,80}$ The combination therapy may be a cost effective alternative for monotherapy by reducing the need for re-treatment.

Combination of different anti-VEGF therapies: We can inhibit VEGF in various ways. The induction therapy with a pan-VEGF inhibitor (ranibizumab or bevacizumab) will provide an optimal regression of the CNV and an improvement in vision and then the anti-VEGF165 specific inhibitor (pegaptanib) may maintain vessel regression with a better safety profile.

\section{Surgery}

Numerous surgical approaches have been developed to treat the exudative form of AMD. such as surgical removal of sub-foveal CNV, removal of sub-foveal hemorrhage, macular translocation, and transplantation of the pigment epithelium.

Surgical removal of the CNV: Removal of the CNV together with extensive hemorrhage in AMD was first described by de Juan in $1988 .{ }^{81}$ The first visual results of membrane excision were disappointing with visual improvement in only $0 \%$ to $33 \%$ of the cases. ${ }^{82-84}$ Evaluation of the removal of sub-foveal CNV compared with observation has been conducted between 1997 and 2003 by the Sub-macular Surgery Trials (SST). The SST showed that this surgical alternative therapy did not improve vision. ${ }^{85}$ A retrospective meta-analysis evaluating 647 cases of sub-retinal membrane excision in AMD subjects showed that improvement was achieved in about $33 \%$ and deterioration occurred in $27 \%$. Moreover, the recurrence rate of CNV was approximately $25 \%,{ }^{86}$ and the progression of the atrophic scar size led to further visual loss. In a patient with recent macular hematoma secondary to $\mathrm{CNV}$, different surgical options may be considered. The pneumatic displacement of the sub-macular hemorrhage with SF6 or C3F8 may allow an improvement of the visual acuity. ${ }^{87}$ More aggressive options including three-port vitrectomy, eventual TPA injection, hematoma removal, CNV excision, and gas tamponade have been proposed with variable functional and anatomical results. ${ }^{88}$ Despite these limited results, there are still some indications for sub-macular surgery, such as for patients with 
low preoperative visual acuity due to large hemorrhagic or fibrotic membranes.

Retinal rotation techniques: The first retinal translocation was done by Machemer in $1993 .{ }^{89}$ The development of a partial retinal rotation combined with a scleral shortening has been tested for several years. ${ }^{90,91}$ Because of the very small angle of rotation, the high rate of recurrence (approximately $50 \%$ ), and the availability of other therapies (vPDT), this technique is no longer implemented. A complete $360^{\circ}$ retinotomy, which allows a higher rotation angle of the retina, has been proposed in the second eye-affected patients. ${ }^{92}$ Long-term reports have shown favorable visual results with $52 \%$ of the subjects having one or more lines of improvement, specifically reading vision and contrast sensitivity after one year. ${ }^{93-95}$ A high rate of PVR (approximately $30 \%$ of the cases in inexperienced hands and between $8 \%$ and $18 \%$ in experienced hands) limits the use of this surgical technique. ${ }^{96}$ However, retinal rotation with $360^{\circ}$ retinotomy may be an alternative in a very large $\mathrm{CNV}$, when it does not respond to new therapies or when it is associated with large hematomas.

RPE transplantation: The disappointing visual results after CNV excision were explained by the simultaneous mechanical removal of the RPE layer and the transplantation of the RPE seemed to be a logical solution to restore vision. Currently, different techniques of autologous transplantation of the RPE are under evaluation. ${ }^{97-102}$ The iris pigment epithelial transplantation has been proposed, but this tissue is incapable of expressing crucial enzymes of the retinoid visual cycle. ${ }^{103}$ Investigators proposed the use of RPE suspension cells harvested through a nasal retinotomy at the beginning of the surgery and transplanted in the sub-retinal macular space after the excision of the CNV. ${ }^{104,105}$ A prospective trial was conducted with autologous suspension cell transplantation after membrane excision compared to membrane excision alone. At 12 months, visual improvement of two or more lines was achieved in $52.5 \%$ of the transplantation group (21.5\% in the excision alone group), 32.5\% remained the same, and $15 \%$ had a decrease of vision $(21.5 \%$ in the excision alone group). The statistical analysis of far visual acuity showed just a trend in favor of the transplanted group, but the statistical analysis of the multifocal ERGs showed a significant difference between the two groups, with better results in the transplanted group..$^{99}$ Another transplantation technique using a full thickness RPE-choroid sheet has been proposed by some researchers with interesting results regarding the long-term survival and the revascularization of the transplanted tissue. ${ }^{101-106}$ This technique uses a RPE-choroid flap taken in the superior mid-periphery, which is directly introduced through the macular retinotomy into the sub-retinal space. This particular technique, however, seems to be traumatic and presents a high rate of PVR. ${ }^{101}$

The two main limitations of "one-time" autologous transplantation techniques are the graft size and the quality of the RPE and the Bruch's membrane. Culturing prior to transplantation may offer the potential to at least partially influence or reverse aging and the lipofuscin load per cell might be reduced by dilution during cell division. This "rejuvenation" process may also be combined with a potential gene defect correction. ${ }^{107}$ Unfortunately, the right surgical technique (with a prosthetic Bruch's membrane) and a viable method of culturing are not yet available. RPE-like cells generated from embryonic stem cells, neural stem cells, or bone marrow derived cells, however, may represent the future of the RPE transplantation in AMD. ${ }^{108}$

\section{End stage bilateral AMD (atrophic or exudative): low vision rehabilitation}

At the end stages of exudative or atrophic macular degeneration, when previously described treatments have been unsuccessful, patients may become severely visually impaired. This may cause significant disability, with difficulties in reading and daily activities, all of which may impact on quality of life. ${ }^{109,110}$ In such situations, low vision rehabilitation should be offered to the patient. ${ }^{111}$ In low vision rehabilitation, people are taught to use their remaining vision more effectively. Using a variety of visual aids may allow the patient to become more independent. Most of the time, low vision rehabilitation provides high patient satisfaction with functional and subjective improvements. ${ }^{112-115}$ The rehabilitation of a visually impaired individual may involve a variety of treatment modalities including prescription eyewear, optical devices, electronic aids, adaptive computer software, glare control, modification of the patient's environment, counseling and education of the patient and family, skills training, independent living aids, occupational therapy, mental health intervention, orientation and mobility training, and driving rehabilitation.

In summary, low vision rehabilitation has to be offered to each patient with bilateral advanced AMD complaining of a loss of vision. Low vision aid may be started simultaneously with other therapies before the onset of significant disability.

Recent advances in the treatment of CNV due to AMD have led to major improvements in anatomical and functional results. The prognosis of exudative AMD has completely changed in the last few years. Since the cost of these recent therapies has dramatically increased, the expenses for the 
individual patient has also risen. ${ }^{116}$ A value-based medicine cost utility analysis was performed on different interventions for neovascular AMD to assess the value that each confers to the patient. ${ }^{117}$ Laser therapy confers $4.4 \%$ of value gain, pegaptanib a $5.9 \%$ gain, vPDT an $8.1 \%$ gain and ranibizumab a $15 \%$ gain, which is considered quite high. To put it into perspective, HMG-CoA reductase inhibitors (statins) given for hyperlipidemia confer only a $6.3 \%$ value gain.

\section{Conclusion}

Over the last 20 years, a multitude of clinical trials have evaluated the efficacy of various treatment modalities for neovascular AMD. Thermal laser successfully prevented the proliferation of $\mathrm{CNV}$; however, visual loss and recurrences impaired the treatment benefit. Using non-thermal laser energy through vPDT appeared as a healthy alternative, but again, it was unsatisfying to both the patient and treating clinician given the inability to improve vision in a majority of patients. As we begin to better understand the pathophysiology of CNV and the role of VEGF in its development and persistence, newer pharmacologic interventions have led to previously unattainable results regarding improvements in vision. But again, we are faced with a new problem. We are far better at initiating the medication than we are at stopping it. Just as oncologists treat cancer with various chemotherapies that act in concert, we also are beginning to experiment with combination therapy in an attempt to discontinue the cycle of repetitive treatment. Although it appears promising, retrospective and small prospective studies are no substitute for large, randomized, controlled trials. As our understanding of the disease continues to grow at the molecular level, investigators are simultaneously exploring other treatment venues that may offer a more long-term solution, such as the inhibition of gene expression and signal transduction. In short, we are making headways in the treatment of neovascular AMD, but there is still much to be explored and learned, particularly in its prevention.

\section{Disclosures}

No financial support or grants were utilized for this study. The authors do not have financial disclosures or competing interests in the presented topic.

\section{References}

1. Kahn HA, Leibowitz HM, Ganley JP, et al. The Framingham Eye Study. I. Outline and major prevalence findings. Am J Epidemiol. 1977;106(1):17-32.

2. Klein BE, Linton KL. Prevalence of age-related maculopathy. The Beaver Dam Eye Study. Ophthalmology. 1992;99(6):933-43.
3. Klein BE, Klein R. Cataracts and macular degeneration in older Americans. Arch Ophthalmol. 1982;100(4):571-3.

4. Mitchell P, Smith W, Attebo K, Wang JJ. Prevalence of age-related maculopathy in Australia The Blue Mountains Eye Study, Ophthalmology. 1995;102(10):1450-60.

5. Complications of Age-Related Macular Degeneration Prevention Trial Study Group. The Complications of Age-Related Macular Degeneration Prevention Trial (CAPT):rationale, design and methodology. Clin Trials. 2004;1:91-107.

6. Friedman DS, O’Colmain BJ, Munoz B, et al; Eye Diseases Prevalence Research Group, 2004. Prevalence of age-related macular degeneration in the United States. Arch Ophthalmol. 2004;122(4):564-72.

7. Thylefors B. A global initiative for the elimination of avoidable blindness. Am J Ophthalmol. 1998;125(1):90-93.

8. Bressler NM, Bressler SB, Fine SL. Age-related macular degeneration. Surv Ophthalmol. 1988;32(6):375-413.

9. Votruba M, Gregor Z. Neovascular age-related macular degeneration: present and future options. Eye. 2001;15(3):424-29.

10. Michels S, Schmidt-Erfurth U, Rosenfeld PJ. Promising new treatments for neovascular age-related macular degeneration. Expert Opin Investig Drugs. 2006;15(7):779-93.

11. A randomized, placebo-controlled, clinical trial of high-dose supplementation with vitamins $\mathrm{C}$ and $\mathrm{E}$, beta carotene, and zinc for age-related macular degeneration and vision loss:AREDS report no. 8 Arch Ophthalmol. 2001;119:1417-36.

12. Omenn GS, Goodman GE, Thornquist MD, et al. Effects of a combination of beta carotene and vitamin A on lung cancer and cardiovascular disease. $N$ Engl J Med. 1996;334:1150-5.

13. The effect of vitamin $E$ and beta carotene on the incidence of lung cancer and other cancers in male smokers. The Alpha-Tocopherol, Beta Carotene Cancer Prevention Study Group. N Engl J Med. 1994;330:1029-35.

14. Obana A, Hiramitsu T, Gohto Y, et al. Macular carotenoid levels of normal subjects and age-related maculopathy patients in a Japanese population. Ophthalmology. 2008;115(1):147-57.

15. Chew EY, SanGiovanni JP. Lutein. Encyclopedia of Dietary Supplements. Marcel Dekker, Inc; 2005. p 409-20.

16. SanGiovanni JP, Chew EY. The role of omega-3 LCPFA in health and disease of the retina. Prog Retin Eye Res. 2005;24(1):87-138.

17. Seddon JM, Cote J, Rosner B. Progression of age-related macular degeneration:Association with dietary fat, transunsaturated fat, nuts, and fish intake. Arch Ophthalmol. 2003;121(12):1728-37.

18. SanGiovanni JP, Chew EY, Clemons TE, Seddon JM, Klein R; Age-Related Eye Disease Study (AREDS) Research Group. Dietary lipids intake and incident advanced Age-Related Macular Degeneration (AMD) in the Age-Related Eye Disease Study (AREDS). Annual Meeting, May 2005, Association for Research in Vision and Ophthalmology (ARVO), Fort Lauderdale, FL.

19. Macular Photocoagulation Study Group. Argon laser photocoagulation for neovascular maculopathy. Five-year results from randomized clinical trials. Arch Ophthalmol. 1991;109:1109-14.

20. Macular Photocoagulation Study Group. Laser photocoagulation for juxtafoveal choroidal neovascularization. Five-year results from randomized clinical trials. Arch Ophthalmol. 1994;112:500-9.

21. Macular Photocoagulation Study Group. Laser photocoagulation of subfoveal neovascular lesions of age-related macular degeneration. Updated findings from two clinical trials. Arch Ophthalmol. 1993;111:1200-09.

22. Macular Photocoagulation Study Group. Laser photocoagulation of subfoveal neovascular lesions in age-related macular degeneration. Results of a randomized clinical trial. Arch Ophthalmol. 1991;109:1220-31.

23. Macular Photocoagulation Study Group. Laser photocoagulation of subfoveal recurrent neovascular lesions in age-related macular degeneration. Results of a randomized clinical trial. Arch Ophthalmol. 1991;109:1232-41.

24. Argon laser photocoagulation for neovascular maculopathy. Five-year results from randomized clinical trials. Macular Photocoagulation Study Group. Arch Ophthalmol. 1991;109:1109-14. 
25. Ciulla TA, Criswell MH, Danis RP, Williams JI, McLane MP, Holroyd KJ. Squalamine lactate reduces choroidal neovascularization in a laser-injury model in the rat. Retina. 2003;23(6):808-14.

26. Ciulla TA, Regillo C, Desa I. A phase II, multi-center, randomized, controlled, masked study of the effects of squalamine lactate in combination with Visudyne in patient with subfoveal neovascularization associated with AMD. ARVO, Fort Lauderdale, 2005.

27. Schmidt-Erfurth U, Laqua H, Schlotzer-Shrehard U, Viestenz A, Naumann GO, Histopathological changes following photodynamic therapy in human eyes. Arch Ophthalmol. 2002;120(6):835-44.

28. Schmidt-Erfurth U, Schlötzer-Schrehard U, Cursiefen C, Michels S, Beckendorf A, Naumann GO. Influence of photodynamic therapy on expression of vascular endothelial growth factor (VEGF), VEGF Receptor 3, and pigment epithelium - derived factor. Invest Ophthalmol Vis Sci. 2003;44(10):4473-80.

29. Bressler NM, Bressler SB, Fine SL, Age-related macular degeneration. Surv Ophthalmol. 1988;32:375-413.

30. Bressler NM. Photodynamic therapy of subfoveal choroidal neovascularization in age-related macular degeneration with verteporfin:two- year results of 2 randomized clinical trials-TAP report 2. Arch Ophthalmol. 2001;119:198-207.

31. Photodynamic therapy of subfoveal choroidal neovascularization in age-related macular degeneration with verteporfin:one-year results of 2 randomized clinical trials - TAP report. Treatment of age-related macular degeneration with photodynamic therapy (TAP) Study Group. Arch Ophthalmol. 1999;117:1329-45.

32. Verteporfin therapy of subfoveal choroidal neovascularization in age-related macular degeneration:two-year results of a randomized clinical trial including lesions with occult with no classic choroidal neovascularization - verteporfin in photodynamic therapy report 2 . Am J Ophthalmol. 2001;131:541-60.

33. Wormald R, Evans J, Smeeth L, Henshaw K. Photodynamic therapy for neovascular age-related macular degeneration. Cochrane Database Syst Rev. 2007;18:(3).

34. Arnold JJ, Blinder KJ, Bressler NM, et al. Treatment of Age-Related Macular Degeneration with Photodynamic Therapy Study Group; Verteporfin in Photodynamic Therapy Study Group. Acute severe visual acuity disease after photodynamic therapy with verteporfin:case reports from randomized clinical trials-TAP and VIP report no. 3. Am J Ophthalmol. 2004;137(4):683-96.

35. Blinder KJ, Bradley S, Bressler NM, et al. Effect of lesion size, visual acuity, and lesion composition on visual acuity change with and without verteporfin therapy for choroidal neovascularization secondary to age-related macular degeneration:TAP and VIP report no. 1. Am J Ophthalmol. 2003;136:407-18.

36. Meyer M, Clauss M, Lepple-Wienhues A, et al. A novel vascular endothelial growth factor encoded by Orf virus, VEGF-E, mediates angiogenesis via signalling through VEGFR-2 (KDR) but not VEGFR-1 (Flt-1) receptor tyrosine kinases. EMBO J. 1999;18(2):363-74.

37. Campochiaro PA. Retinal and choroidal neovascularization. J Cell Physiol. 2000;184(3):301-10.

38. Kusters B, de Waal RM, Wesseling P, et al. Differential effects of vascular endothelial growth factor A isoforms in a mouse brain metastasis model of human melanoma. Cancer Res. 2003;63(17):5408-13.

39. Spyridopoulos I, Luedemann C, Chen D, Kearney M, Chen D, Murohara T, Principe N, Isner JM, Losordo DW. Divergence of angiogenic and vascular permeability signaling by VEGF:inhibition of protein kinase $\mathrm{C}$ suppresses VEGF-induced angiogenesis, but promotes VEGF-induced, NO-dependent vascular permeability. Arterioscler Thromb Vasc Biol. 2002;22(6):901-6.

40. Ferrara N, Kerbel RS. Angiogenesis as a therapeutic target. Nature. 2005;438:967-74.

41. Ferrara N, Gerber HP, LeCouter J. The biology of VEGF and its receptors. Nat Med. 2003;9(6):669-76.

42. Moshfeghi AA, Puliafito CA. Pegaptanib sodium for the treatment of neovascular age-related macular degeneration. Expert Opin Investig Drugs. 2005;14(5):671-82.
43. Gragoudas ES, Adamis AP, Cunningham ET Jr, Feinsod M, Guyer DR; VEGF Inhibition Study in Ocular Neovascularization Clinical Trial Group. N Engl J Med. 2004;351(27):2805-16.

44. VEGF Inhibition Study in Ocular Neovascularization (V.I.S.I.O.N.) Clinical Trial Group, Chakravarthy U, Adamis AP, Cunningham ET Jr, et al. Year 2 efficacy results of 2 randomized controlled clinical trials of pegaptanib for neovascular age-related macular degeneration. Ophthalmology. 2006;113(9):1508-25.

45. Gonzales CR; VEGF Inhibition Study in Ocular Neovascularization (V.I.S.I.O.N.) Clinical Trial Group. Enhanced efficacy associated with early treatment of neovascular age-related macular degeneration with pegaptanib sodium:an exploratory analysis. Retina. 2005;25(7):815-27.

46. Chen Y, Wiesmann C, Fuh G, et al. Selection and analysis of an optimized anti-VEGF antibody:crystal structure of an affinity-matured Fab in complex with antigen. $J$ Mol Biol. 1999;293(4):865-81.

47. Schmidt-Erfurth U. Results from the PIER study. Presented at Asian Pacific Association of Ophthalmologists Annual Meeting (APAO), June 2006, Singapore.

48. Brown DM, Kaiser PK, Michels M, et al; for the ANCHOR Study Group. 2006. Ranibizumab versus verteporfin for neovascular age-related macular degeneration. N Engl J Med. 2006;355:1432-44.

49. Chang TS, Fine JT, Bressler NM. Self-reported Vision-specific Quality of Life at 1 Year in Patients with Neovascular Age-related Macular Degeneration in 2 Phase III Randomized Clinical Trials Of Ranibizumab (Lucentis). IOVS, ARVO 2004. Abstract 5252.

50. Rosenfeld PJ, Brown DM, Heier JS, et al; MARINA Study Group. Ranibizumab for neovascular age-related macular degeneration. $N E n g l$ J Med. 2006;355(14):1419-31.

51. Fung AE, Lalwani GA, Rosenfeld PJ, et al. An optical coherence tomography-guided, variable dosing regimen with intravitreal ranibizumab (Lucentis) for neovascular age-related macular degeneration. Am J Ophthalmol. 2007;143(4):566-83.

52. Brown DM, Regillo CD. Anti-VEGF Agents in the treatment of neovascular age-related macular degeneration:applying clinical trial results to the treatment of everyday patients. Am J Ophthalmol. 2007;144(4):627-37.

53. Michels S, Rosenfeld PJ, Puliafito CA, Systemic bevacizumab (Avastin) therapy for Neovascular age-related macular degeneration twelve-week results of an uncontrolled open-label clinical study. Ophthalmology. 2005;112:1035-47.

54. Barker DL, Brooks HL, Steinmetz RL, Newell CK, Puliafito CA, Rosenfeld PJ. Intravitreal bevacizumab compared with photodynamic therapy for juxtafoveal choroidal neovascular membranes in age related macular degeneration. Abstract:ASRS. EVRS Cannes Retina Festival 2006, France, September 8-13.

55. Rich RM, Rosenfeld PJ, Puliafito CA, et al. Short-term safety and efficacy of intravitreal bevacizumab (Avastin) for neovascular age-related macular degeneration. Retina. 2006;26(5):495-511.

56. Spaide RF, Laud K, Fine HF, et al. Intravitreal bevacizumab treatment of choroidal neovascularization secondary to age-related macular degeneration. Retina. 2006;26:383-90.

57. Williams, DF, Bennett SR, Cantrill HL, et al. Intravitreal bevacizumab $\left(\right.$ Avastin $\left.^{\mathbb{R}}\right)$ for primary treatment of neovascular AMD. Abstract:ASRS. EVRS Cannes Retina Festival 2006, France, September 8-13.

58. Avery RL, Pieramici DJ, Rabena MD, Castellarin AA, Nasir MA, Giust MJ. Intravitreal bevacizumab (Avastin) for neovascular age-related macular degeneration. Ophthalmology. 2006;113:363-72.

59. Shahar J, Avery RL, Heilweil G, et al. Electrophysiologic and retinal penetration studies following intravitreal injection of bevacizumab (Avastin). Retina. 2006;26(3):262-9.

60. Chang LK, Sarraf D. Tears of the retinal pigment epithelium:an old problem in a new era. Retina. 200;27(5):523-34.

61. Chan CK, Lin SG. Retinal pigment epithelial tear after ranibizumab therapy for subfoveal fibrovascular pigment epithelial detachment. Eur J Ophthalmol. 200;17(4):674-6. 
62. Ronan SM, Yoganathan P, Chien FY, et al. Retinal pigment epithelium tears after intravitreal injection of bevacizumab (avastin) for neovascular age-related macular degeneration. Retina. 200;27(5):535-40.

63. Spandau UH, Jonas JB. Retinal pigment epithelium tear after intravitreal bevacizumab for exudative age-related macular degeneration. $\mathrm{Am} \mathrm{J}$ Ophthalmol. 2006;142(6):1068-70.

64. Weinberger AW, Thiel M, Mohammadi B, Theofylaktopoulos I, 1G, Walter P. Retinal pigment epithelium tears after intravitreal bevacizumab in pigment epithelium detachment. Am J Ophthalmol. 2007;144(2):294-6.

65. Gillies MC, Wong TY. Ranibizumab for neovascular age-related macular degeneration. $N$ Engl J Med. 2007;356(7):748-9; author reply 749-50.

66. Wong TY, Liew G, Mitchell P. Clinical update:new treatments for age-related macular degeneration. Lancet. 2007;370(9583):204-6.

67. Schmidt-Erfurth U, Schlotzer-Schrehard U, Cursiefen C, Michels S, Beckendorf A, Naumann GO. Influence of photodynamic therapy on expression of vascular endothelial growth factor (VEGF), VEGF receptor 3, and pigment epithelium-derived factor. Invest Ophthalmol Vis Sci. 2003;44(10):473-80.

68. Kaiser PK. Verteporfin therapy in combination with triamcinolone: published studies investigating a potential synergistic effect. Curr Med Res Opin. 2005;21(5):705-13.

69. Rechtman E, Danis RP, Pratt LM, Harris A. Intravitreal triamcinolone with photodynamic therapy for subfoveal choroidal neovascularisation in age related macular degeneration. BrJ Ophthalmol. 2004;88(3):344-7.

70. Spaide RF, Sorenson J, Maranan L. Combined photodynamic therapy with verteporfin and intravitreal triamcinolone acetonide for choroida neovascularization. Ophthalmology. 2003;110(8):1517-25.

71. Augustin AJ, Schmidt-Erfurth U. Verteporfin therapy combined with intravitreal triamcinolone in all types of choroidal neovascularization due to age-related macular degeneration. Ophthalmology. 2006;113(1):14-22.

72. Russell SR, Hudson HL, Jerdan JA; Anecortave Acetate Clinical Study Group. Anecortave acetate for the treatment of exudative age-related macular degeneration - a review of clinical outcomes. Surv Ophthalmol. 2007;52:79-90.

73. Regillo CD, D'Amico DJ, Mieler WF, Schneebaum C, Beasley CH, Sullins GT. Clinical safety profile of posterior juxtascleral depot administration of anecortave acetate $15 \mathrm{mg}$ suspension as primary therapy or adjunctive therapy with photodynamic therapy for treatment of wet age-related macular degeneration. Surv Ophthalmol. 2007;52:70-8.

74. Kaiser PK. Verteporfin photodynamic therapy and anti-angiogenic drugs:potential for combination therapy in exudative age-related macular degeneration. Curr Med Res Opin. 2007;23(3):477-87.

75. Petermeier K, Tatar O, Inhoffen W, et al. Verteporfin photodynamic therapy induced apoptosis in choroidal neovascular membranes. Br J Ophthalmol. 2006;90(8):1034-9.

76. VEGF Inhibition Study in Ocular Neovascularization (V.I.S.I.O.N.) Clinical Trial Group; D’Amico DJ, Masonson HN, Patel M, et al. Pegaptanib sodium for neovascular age-related macular degeneration: two-year safety results of the two prospective, multicenter, controlled clinical trials. Ophthalmology. 2006;113(6):992-1001.

77. Heier JS, Boyer DS, Ciulla TA, et al; FOCUS Study Group.Ranibizumab combined with verteporfin photodynamic therapy in neovascular age-related macular degeneration:year 1 results of the FOCUS Study. Arch Ophthalmol. 2006;124(11):1532-42.

78. Schmidt-Erfurth U, Gabel P, Hohman T; PROTECT Study Group Preliminary results from an open-label, multicenter, phase II study assessing the effects of same-day administration of ranibizumab (Lucentis(TM) and verteporfin PDT (PROTECT Study). Program and abstracts of the Association for Research in Vision and Ophthalmology; April 30-May 4, 2006; Fort Lauderdale, Florida. Abstract 2960.

79. Dhalla MS, Shah GK, Blinder KJ, Ryan EH Jr, Mittra RA, Tewari A. Combined photodynamic therapy with verteporfin and intravitreal bevacizumab for choroidal neovascularization in age-related macular degeneration. Retina. 2006;26(9):988-93.
80. Ladewig MS, Karl SE, Hamelmann V, et al. Combined intravitreal bevacizumab and photodynamic therapy for neovascular age-related macular degeneration. Graefes Arch Clin Exp Ophthalmol. 2008; 246:17-25.

81. de Juan JrE. Vitreous surgery for hemorrhagic and fibrous complications of age-related macular degeneration. Am J Ophthalmol. 1988;105:25-9.

82. Berger AS, Kaplan HJ. Clinical experience with the surgical removal of subfoveal neovascular membranes. Short-term postoperative results. Ophthalmology. 1992;99(6):969-75; discussion 975-6.

83. Schachat AP. Should we recommend vitreous surgery for patients with choroidal neovascularization? Arch Ophthalmol. 1994;112(4):459-61.

84. Thomas MA, Dickinson JD, Melberg NS, Ibanez HE, Dhaliwal RS. Visual results after surgical removal of subfoveal choroidal neovascular membranes. Ophthalmology. 1994;101(8):1384-96.

85. Bressler NM, Hawkins BS, Bressler SB, Miskala PH, Marsh MJ; Submacular Surgery Trials Research Group. Clinical trial performance of community- vs university-based practices in the submacular surgery trials (SST):SST report no. 2. Arch Ophthalmol. 2004;122(6):857-63.

86. Falkner CI, Leitich H, Frommlet F, Bauer P, Binder S. The end of submacular surgery for age-related macular degeneration? A meta-analysis. Graefes Arch Clin Exp Ophthalmol. 2007;245(4):490-501.

87. Ron Y, Ehrlich R, Axer-Siegel R, Rosenblatt I, Weinberger D. Pneumatic displacement of submacular hemorrhage due to age-related macular degeneration. Ophthalmologica. 2007;221(1):57-61.

88. Singh RP, Patel C, Sears JE. Management of subretinal macular haemorrhage by direct administration of tissue plasminogen activator. Br J Ophthalmol. 2006;90(4):429-31.

89. Machemer R, Steinhorst UH. Retinal separation, retinotomy, and macular relocation:II. A surgical approach for age-related macular degeneration? Graefes Arch Clin Exp Ophthalmol. 1993;231(11):635-41.

90. de Juan E Jr, Loewenstein A, Bressler NM, Alexander J. Translocation of the retina for management of subfoveal choroidal neovascularization II:a preliminary report in humans. Am J Ophthalmol. 1998;125(5):635-46.

91. Lewis H, Kaiser PK, Lewis S, Estafanous M. Macular translocation for subfoveal choroidal neovascularization in age-related macular degeneration: a prospective study. Am J Ophthalmol. 1999;128(2):135-46.

92. Eckardt C, Eckardt U, Conrad HG. Macular rotation with and without counter-rotation of the globe in patients with age-related macular degeneration. Graefes Arch Clin Exp Ophthalmol. 1999;237(4):313-25.

93. Mruthyunjaya $P$, Stinnett SS, Toth CA. Change in visual function after macular translocation with 360 degrees retinectomy for neovascular age-related macular degeneration. Ophthalmology. 2004;111(9):1715-24.

94. Toth CA, Freedman SF. Macular translocation with 360-degree peripheral retinectomy impact of technique and surgical experience on visual outcomes. Retina. 2001;21(4):293-303.

95. Toth CA, Lapolice DJ, Banks AD, Stinnett SS. Improvement in near visual function after macular translocation surgery with 360-degree peripheral retinectomy. Graefes Arch Clin Exp Ophthalmol. 2004;242(7):541-48.

96. Pertile G, Claes C. Macular translocation with 360 degree retinotomy for management of age-related macular degeneration with subfoveal choroidal neovascularization. Am J Ophthalmol. 2002;134(4):560-5.

97. MacLaren RE, Uppal GS, Balaggan KS, Tufail A, Munro PM, Milliken AB, Ali RR, Rubin GS, Aylward GW, da Cruz L. Autologous transplantation of the retinal pigment epithelium and choroid in the treatment of neovascular age-related macular degeneration. Ophthalmology. 2007;114(3):561-70.

98. Aisenbrey S, Lafaut BA, Szurman P, et al. Iris pigment epithelial translocation in the treatment of exudative macular degeneration: a 3-year follow-up. Arch Ophthalmol. 2006;124(2):183-8.

99. Binder S, Stanzel BV, Krebs I, Glittenberg C. Transplantation of the RPE in AMD. Prog Retin Eye Res. 2007;26(5):516-4. 
100. Heussen FM, Fawzy NF, Joeres S, Lux A, Maaijwee K, Meurs JC, Kirchhof B, Joussen AM. Autologous translocation of the choroid and RPE in age-related macular degeneration:1-year follow-up in 30 patients and recommendations for patient selection. Eye. 2008;22:7999-807.

101. Joussen AM, Heussen FM, Joeres S, et al. Autologous translocation of the choroid and retinal pigment epithelium in age-related macular degeneration. Am J Ophthalmol. 2006;142(1):17-30.

102. Maaijwee K, Heimann H, Missotten T, Mulder P, Joussen A, van Meurs J. Retinal pigment epithelium and choroid translocation in patients with exudative age-related macular degeneration:long-term results. Graefes Arch Clin Exp Ophthalmol. 2007;245:1681-9.

103. Cai H, Shin MC, Tezel TH, Kaplan HJ, Del Priore LV. Use of iris pigment epithelium to replace retinal pigment epithelium in age-related macular degeneration:a gene expression analysis. Arch Ophthalmol. 2006;124(9):1276-85.

104. Binder S, Stolba U, Krebs I, et al. Transplantation of autologous retinal pigment epithelium in eyes with foveal neovascularization resulting from age-related macular degeneration:a pilot study. Am J Ophthalmol. 2002;133(2):215-25.

105. Binder S, Krebs I, Hilgers RD, et al. Outcome of transplantation of autologous retinal pigment epithelium in age-related macular degeneration: a prospective trial. Invest Ophthalmol Vis Sci. 2004;45(11):4151-60.

106. Van Meurs JC, ter Averst E, Hofland LJ, et al. Autologous peripheral retinal pigment epithelium translocation in patients with subfoveal neovascular membranes. Br J Ophthalmol. 2004;88(1):110-3.

107. Kanuga N, Winton HL, Beauchéne L. Characterization of genetically modified human retinal pigment epithelial cells developed for in vitro and transplantation studies. Invest Ophthalmol Vis Sci. 2002;43:546-55.
108. Li Y, Reca RG, Atmaca-Sonmez P, Ratajczak MZ, Ildstad ST, Kaplan HJ, Enzmann V. Retinal pigment epithelium damage enhances expression of chemoattractants and migration of bone marrow-derived stem cells. Invest Ophthalmol Vis Sci. 2006;47(4):1646-52.

109. Mangione CM, Gutierrez PR, Lowe G, Orav EJ, Seddon JM. Influence of age-related maculopathy on visual functioning and health-related quality of life. Am J Ophthalmol. 1999;128(1):45-53.

110. Lamoureux EL, Pallant JF, Pesudovs K, Hassell JB, Keeffe JE. The Impact of Vision Impairment Questionnaire:an evaluation of its measurement properties using Rasch analysis. Invest Ophthalmol Vis Sci. 2006;47(11):4732-41.

111. Hassell JB, Lamoureux EL, Keeffe JE. Impact of age related macular degeneration on quality of life. Br J Ophthalmol. 2006;90(5):593-6.

112. Lamoureux EL, Pallant JF, Pesudovs K, Rees G, Hassell JB, Keeffe JE. The effectiveness of low-vision rehabilitation on participation in daily living and quality of life. Invest Ophthalmol Vis Sci. 2007;48(4):1476-82.

113. Massof RW. A system model for low vision rehabilitation. I. Basic concepts. Optom Vis Sci. 1995;72(10):72-36.

114. Reeves BC, Harper RA, Russell WB. Enhanced low vision rehabilitation for people with age related macular degeneration:a randomised controlled trial. Br J Ophthalmol. 2004;88(11):1443-9.

115. Scott IU, Smiddy WE, Schiffman J, Feuer WJ, Pappas CJ. Quality of life of low-vision patients and the impact of low-vision services. Am J Ophthalmol. 1999;128(1):54-62.

116. Smiddy WE. Relative cost of a line of vision in age-related macular degeneration. Ophthalmology. 2007;114(5):847-54.

117. Brown M. A value-based medecine analysis of neovascular AMD. The Retina society, Boston, Sept 2007. 